\title{
Assessing and Harmonizing Lying Deadwood Volume with Regional Forest Inventory Data in Wallonia (Southern Region of Belgium)
}

\author{
Gauthier Ligot ${ }^{*}$ Philippe Lejeune, Jacques Rondeux and Jacques Hébert
}

Univ. Liège, Gembloux Agro-Bio Tech, Unité de Gestion des Ressources forestières et des Milieux naturels, B-5030 Gembloux, Belgium

\begin{abstract}
Using lying deadwood or coarse woody debris (CWD) as an indicator of biodiversity and of sustainable forest management is on the rise among national and local forest inventories. Nevertheless choosing the most suitable sampling method is difficult as it depends mostly on CWD abundance and dimensions. In addition the CWD volume estimates of different regional inventories are rarely comparable. We therefore tested two generally recommended methods for lying deadwood: line intersect sampling and fixed area sampling. We assessed both methods in plots of the regional forest inventory of Wallonia (southern region of Belgium). Next we developed bridging functions that converts CWD volume estimates to estimates that would have been obtained with different thresholds. Results about precision and time requirement are very slightly in favour of the line intersect sampling method. Nevertheless, we have noted that this method has several drawbacks, especially in the context of a regional and multi-resource inventory. Beside the established bridging functions indicate that CWD volume estimate from the Walloon forest inventories should be reduced by $20 \%$ in order to be internationally harmonized.
\end{abstract}

Keywords: Sampling methods, coarse woody debris, inventory, harmonization, deadwood.

\section{INTRODUCTION}

The protection and the sustainable management of forests have marked a growing interest in coarse woody debris (CWD) around the world. For instance, CAB Abstract ${ }^{\circledR}$ has recorded over 290 scientific publications since 1997 with the words "deadwood" or "coarse woody debris" in the titles, and about $15 \%$ of them deal with assessment or inventory methods.

Deadwood is an indispensable element in forest ecosystems: an entire trophic pyramid depends on its abundance and diversity [1,2]. Moreover it represents an important carbon pool $[3,4]$ that might even enhance natural regeneration [5], increase bark beetle dispersion [6], increase soil stability [7], or improve the quality of aquatic ecosystems [8]. On the other hand amounts of deadwood are often judged insufficient in comparison to what is observed in old growth forests. Deadwood has therefore become a key indicator of the sustainability of forest management.

Consequently monitoring deadwood has been attempted repeatedly mainly through multi-resource inventories. While standing deadwood is usually assessed with the same sampling units as those used for measuring living trees, lying deadwood or CWD are often assessed with specific sampling methods. Several methods have been utilized to assess lying deadwood: fixed area sampling, variable area sampling, line intersect sampling [9-13], perpendicular distance sampling $[14,15]$, point relascope sampling [16-18], transect relascope sampling [18-20], diameter relascope sampling [21], and

Address correspondence to this author at the Univ. Liège, Gembloux AgroBio Tech, Unité de Gestion des Ressources forestières et des Milieux naturels, B-5030 Gembloux, Belgium; Tel: +32-81-622320; Fax: +32-81622301; E-mail: gligot@ulg.ac.be

adaptative cluster sampling [12, 22-24]. Besides those numerous sampling methods, there is still a wide variety of inventory protocols that vary with dimension thresholds, tallying rules, sampling unit size and shape, sampling effort, type of diameter measured, and volume formula. Those characteristics often differ between inventories and could lead to different levels of estimate precision, efficiency, or even bias.

Many authors have already compared several deadwood inventory methods [14, 25-33]. But despite this abundant literature further work was needed to find the most appropriate sampling methods for the purposes and conditions of the regional forest inventory of Wallonia. As a matter of fact the methods to monitor CWD are so numerous that it seems impossible to compare them all under the same field conditions (e.g. deadwood occurrence and deadwood size might influence the precision and efficiency of inventory methods). Moreover most studies compare inventory methods at local scale $[9,27,29-32]$, whereas few concern national or regional inventories [13,33]. In addition national forest inventories use different dimension threshold which leads to incomparable estimates of CWD volume [3436]. Concerns on harmonizing European national forest inventories are recent and have been raised mainly thanks to the COST action E43 ${ }^{1}$. This COST action E43 has proposed international references as well as harmonizing procedures [37].

Firstly we assess two promising sampling techniques of assessing lying deadwood: Fixed area sampling (FAS) and

\footnotetext{
${ }^{1}$ An action of the European program for Cooperation in the field of Scientific and Technical Research (COST). The full name of this action is "Harmonization of National Forest Inventories in Europe: Techniques for Common Reporting"'.
} 
line intersect sampling (LIS). Those two methods were selected for their practicability and their operational advantages. Variable plot radius or other relascopic sampling methods seemed less suitable. Since a dense herbaceous layer covers often CWD, we found relascopic methods less adapted to our conditions. Besides, for carbon assessments, one needs to assess the density of every CWD piece which makes most variable selection method ineffective. Moreover fixed area sampling (FAS) is the most widely used method in Europe to assess lying deadwood in national forest inventories (NFI) [38]. According to the questionnaire realized by the COST action E43, plot surface varies among NFIs between $54 \mathrm{~m}^{2}$ and $706 \mathrm{~m}^{2}$ (corresponding to circular plots of a radius of respectively $6.3 \mathrm{~m}$ and $15 \mathrm{~m}$ ). LIS is, for instance, used by the Swiss Forest Inventory [13] and has been used for a long time in the United States of America to assess log residues, firewood, and more recently deadwood for biodiversity issues and carbon accounting. Both American and Swiss inventories use three different transects per sampling unit.

Secondly we attempt harmonizing LIS and FAS estimates with bridging functions. Harmonization attempts to develop bridges that convert estimates based on national (or regional) definitions to estimates based on standard definitions. Concerning CWD the international reference thresholds are a small-end diameter of $10 \mathrm{~cm}$ and a length of $1 \mathrm{~m}$ (COST action E43). The regional forest inventory of Wallonia uses the same length threshold but a smaller smallend diameter threshold. As a result we develop bridges to harmonize CWD volume estimates.

\section{MATERIALS AND METHODS}

\subsection{Definition of Coarse Woody Debris}

Coarse woody debris (CWD) are sound and rotting pieces of wood located on the ground, that are non-selfsupporting, respect threshold dimensions, have an angle of less than $45^{\circ}$ with a horizontal plane. The thresholds used are the same as those used by the regional forest inventory of Wallonia: length of $1 \mathrm{~m}$ and small-end diameter (SED, see Fig. 1) of $6.4 \mathrm{~cm}$ (girth of $20 \mathrm{~cm}$ ). Length is measured following piece curvature. Debris diameter is measured with a tape rather than with a calliper since cross-sectional shapes often deviates from a circle. Each segment of forked pieces is treated separately and partially buried pieces are fully measured even if it requires digging up CWD extremities. Pieces with diameter sections narrower than the SED were not treated differently. A part of a log might be narrower than the SED because of significant decay or wounding in the middle of the piece, but it is reasonable to assume that this appears locally and that the opposite situation might equally occur.

\subsection{Field Inventory}

The Regional Forest Inventory of Wallonia (RFIW) is a permanent regional inventory that provides information about the sustainable development of forest resources in the southern part of Belgium. RFIW is a single phase, nonstratified, and systematic inventory with approximately 11,000 plots [39]. Deadwood is one of the numerous variables assessed. Dead trees, snags, and CWD are taken into account. RFIW uses three concentric plots for sampling living trees. Those are circular and have a radius of $4.5 \mathrm{~m}, 9 \mathrm{~m}$ or $18 \mathrm{~m}$. CWD have been measured in the plots of 9-m radius (FAS9) since 2000. Any piece bigger than threshold dimensions and that falls inside plot perimeter, is tallied. In the case of a piece overlapping the plot boundary, only the part that fully lies inside the perimeter and respect threshold dimensions is taken into account. For every tallied piece its length (L) and its mid-diameter (MD) were measured (Fig. 1).

In order to compare FAS and LIS, 100 RFIW plots were selected (Fig. 3). As we wanted freshly updated information, we restrained the selection to the plots that were measured by the RFIW after July 2008. Next we selected randomly plots in public forest. The CWD measurements were carried out in spring 2009. Furthermore, field workers of the RFIW also have the possibility to visually assess large CWD accumulations. In our experiment, 10 plots were concerned with visual estimations. Since visual estimation is a third sampling method with poorer accuracy, we did not include these plots in this study.

In those plots CWD were measured in 9-m radius plots (with the previously described method) and along $36-\mathrm{m}$ transects ( LIS36 ). While the Swiss and American inventory use Y-shaped transects, we have preferred using only one line transect per sampling unit as this preserves the designunbiasedness of the estimators we used [40]. The transects were located in such a way that their centers correspond exactly to plot centers. Their orientation was chosen at random. For every tallied piece, girth and tilt were measured at the intersection point with transect. The transect length was limited to $36 \mathrm{~m}$ because it corresponds to the diameter of the largest plot of the RFIW (Fig. 2). Curved pieces have to be tallied several times, but we did not face this particular

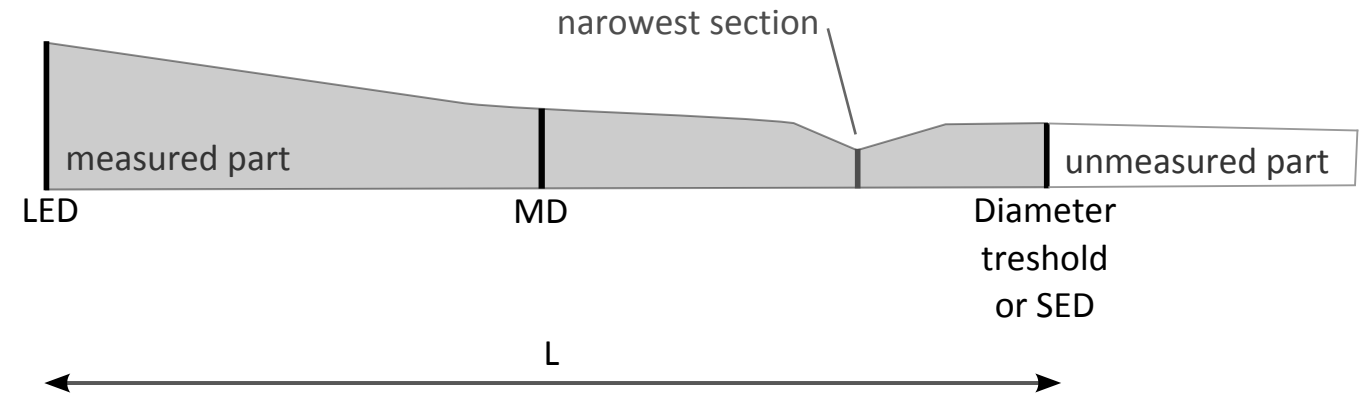

Fig. (1). Scheme of a tallied log. In circular plots, we measured piece mid-diameter (MD) and length (L). Large-end diameter (LED) and small-end diameter (SED) are used to establish bridging functions. The SED is always greater or equal than the diameter threshold. 
situation. The distances between debris-transect intersection point and plot centers were also measured in order to simulate the use of shorter transects (transects of 18, 21, 24, 27, 30, and $33 \mathrm{~m}$ denoted in the thereafter as LIS18, LIS21, LIS24, LIS27, LIS30, LIS33). Only 51 plots and transects were used to assess the measurement duration, since the other plots and transects were performed by different field crews.

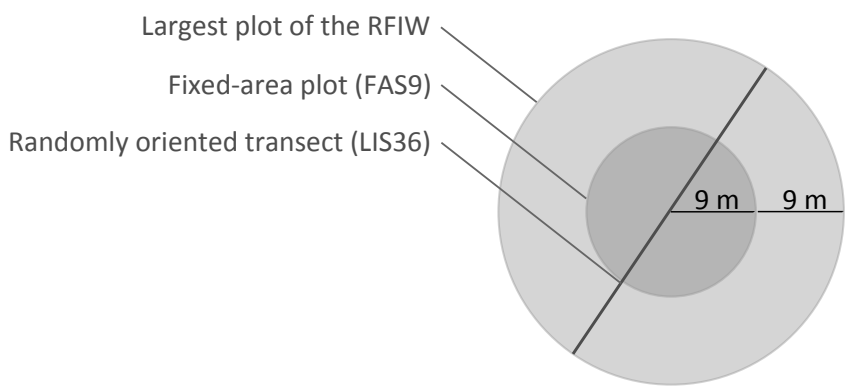

Fig. (2). Sampling unit scheme. LIS36 corresponds to 36-m transect located so that its center corresponds to the sampling unit center of the RFIW and is totally included in the biggest sampling unit used by the RFIW.

\subsection{Study Area}

Every selected plot (Fig. 3) is in public and productive forests in which CWD quantities and dimensions are likely to be unpredictable because deadwood spatial variability is somehow the result of human activity [41]. Nevertheless, the sampled stands are for the most part even-aged $(70 \%)$. Uneven-aged and coppice with standards stands occur in respectively $18 \%$ and $12 \%$ of the plots. The sampled stands are mainly dominated by beech (Fagus sylvatica L., 22.5\%), spruce (Picea abies L. 20.6\%), indigenous oak (Quercus petraea (Matt) Lieb. and Quercus robur L., 17.6\%). As additional tree species, mapple (Acer pseudoplatanus L.), ash (Fraxinus Excelsior L.), douglas-fir (Pseudotsuga menziesii (Mirb.) Franco), and larch (Larix sp.) occured as well in a few plots. The mean basal area is $27 \mathrm{~m}^{2} / \mathrm{ha}$ and varies between $1.3 \mathrm{~m}^{2} / \mathrm{ha}$ and $55 \mathrm{~m}^{2} / \mathrm{ha}$. Even-aged stands are intensively managed with clearcuts and thinnings while mixed and uneven-aged stands are generally managed with the single-tree selection method. Coniferous and broadleaved stands are usually thinned every 6 and 12 years respectively.

\subsection{Volume Calculations}

\subsubsection{Fixed-Area Sampling}

The volume of single CWD $\left(v_{i j}\right)$ was computed with Huber's formula (equation 1). The general formula used to compute the estimate of the mean CWD volume per hectare $(\bar{v})$ can then be expressed as in equation 3 [42].

$$
\begin{aligned}
& v_{j i}=\pi d_{j i}^{2} l_{j i} / 4 \\
& \hat{v}_{j}=\frac{10,000}{a_{j}} \sum_{i=1}^{m_{j}} v_{i j} \\
& \bar{v}=\frac{1}{n} \sum_{j=1}^{n} \hat{v}_{j}=\frac{10,000}{n} \sum_{j=1}^{n} \frac{1}{a_{j}} \sum_{i=1}^{m_{j}} v_{i j}
\end{aligned}
$$

$n$ is the number of plots; $a_{j}$ the area of the plot $j\left(m^{2}\right)$; $m_{j}$ the number of CWD tallied in plot $j ; d_{i j}$ the middiameter of the piece $i j(m) ; l_{i j}$ the length of the piece $i j$ (m); $\hat{v}_{j}$ the estimate of the CWD volume per hectare from plot $j$.

\subsubsection{Line Intersect Sampling}

Since the probability of sampling a piece of deadwood is proportional to its length and since only the diameter at the debris-transect intersection point was measured, we had to use a specific estimator which is known to be unbiased if we assume that transect or debris are oriented at random (equation 4 and 5) [10, 12].

$$
\begin{aligned}
& \hat{v}_{j}=\frac{10,000 \pi^{2}}{8 L_{j} \cos \left(\phi_{j}\right)} \sum_{i=1}^{m_{j}} \frac{d_{j i}^{2}}{\cos \left(\delta_{i j}\right)} \\
& \bar{v}=\frac{10,000 \pi^{2}}{8 n} \sum_{j=1}^{n} \frac{1}{L_{j} \cos \left(\phi_{j}\right)} \sum_{i=1}^{m_{j}} \frac{d_{i j}^{2}}{\cos \left(\delta_{i j}\right)}
\end{aligned}
$$

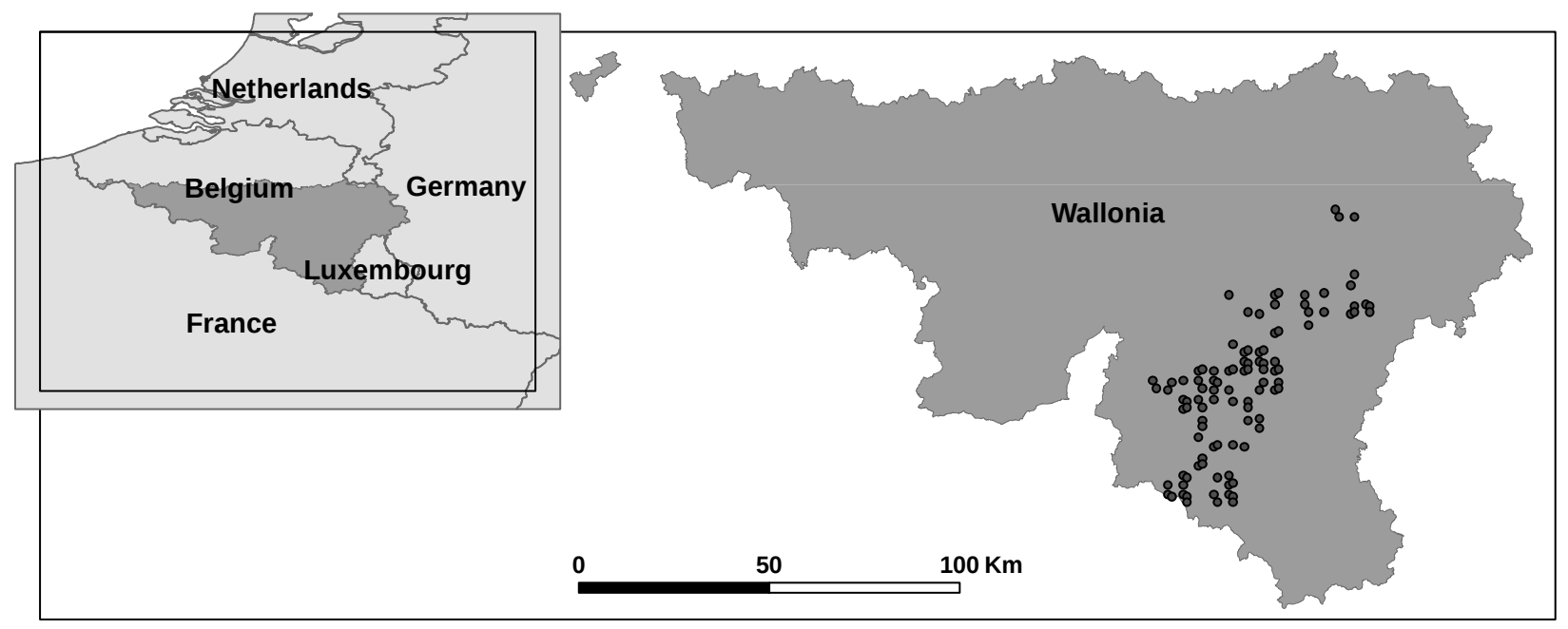

Fig. (3). Location of the sampling plots. 
$n$ is the number of transects; $L_{j}$ the length of transect $j$ $(m) ; \phi_{j}$ the ground slope along the transect $j ; m_{j}$ the number of CWD intersected by transect $j ; d_{i j}$ the diameter of the piece $i j(m)$; and $\delta_{i j}$ the piece's orientation in relation to a horizontal plane.

The simulated transects are centered on plot center and their length vary between $18 \mathrm{~m}$ and $36 \mathrm{~m}$ which correspond to the plot diameters used by the RFIW. Debris are simply included in the computations if their distance from debristransect intersection point to plot center is less than half of the simulated transect length.

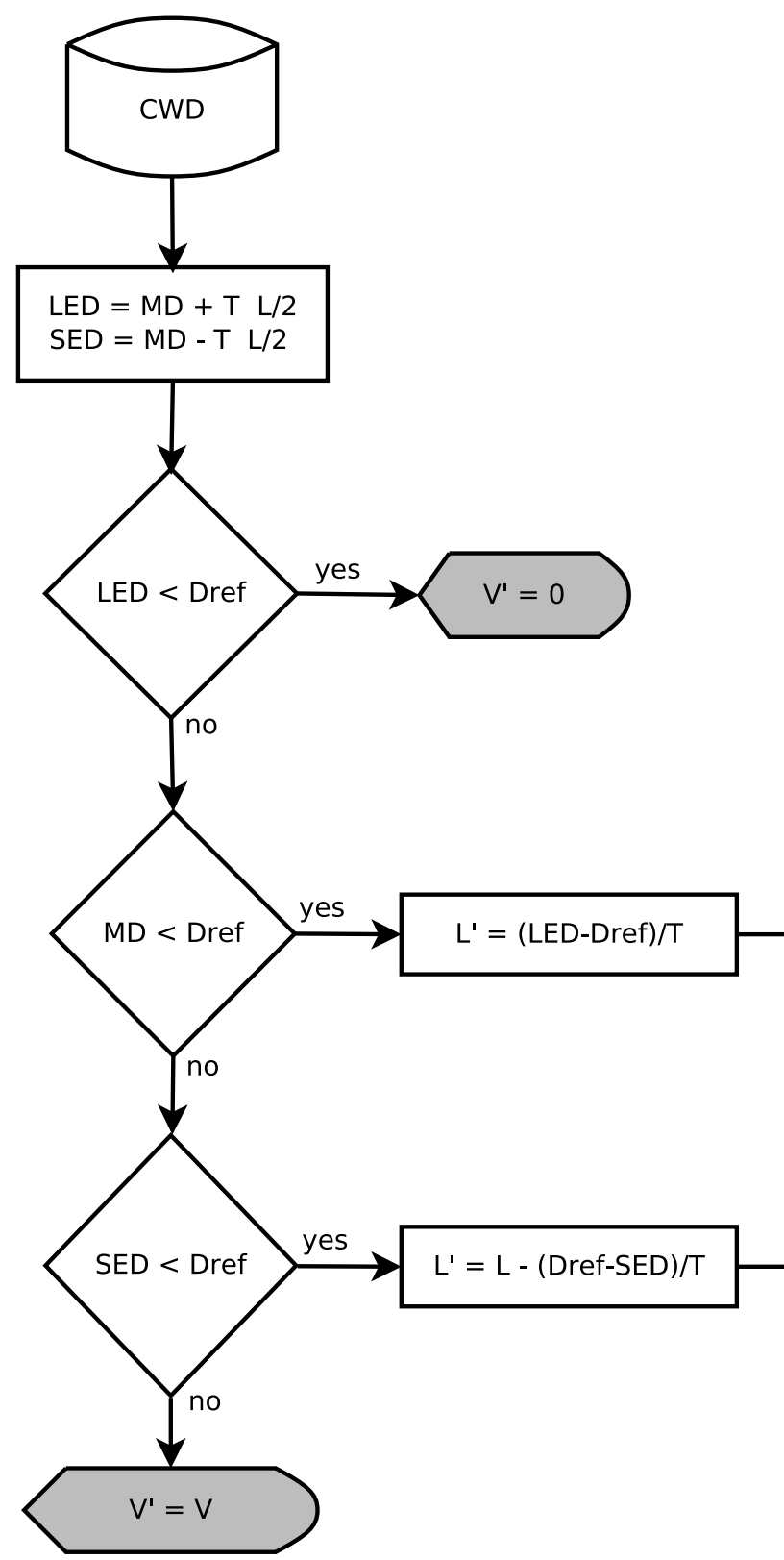

\subsubsection{Bridging Functions}

Bridging functions aim at converting CWD volume estimates into standardized volume estimates that respect other definitions than those that have been used by field operators. In this paper only a change in diameter threshold is illustrated because the length threshold used by the RFIW already corresponds to the international reference proposed by the COST action E43. Two distinct methods have been developed in order to harmonize FAS and LIS estimates.

Firstly, the volume of CWD measured in plots was reduced, when applying the calculation scheme depicted in Fig. (4). The transformed volume was next aggregated per plot in order to evaluate the effect of using SED thresholds

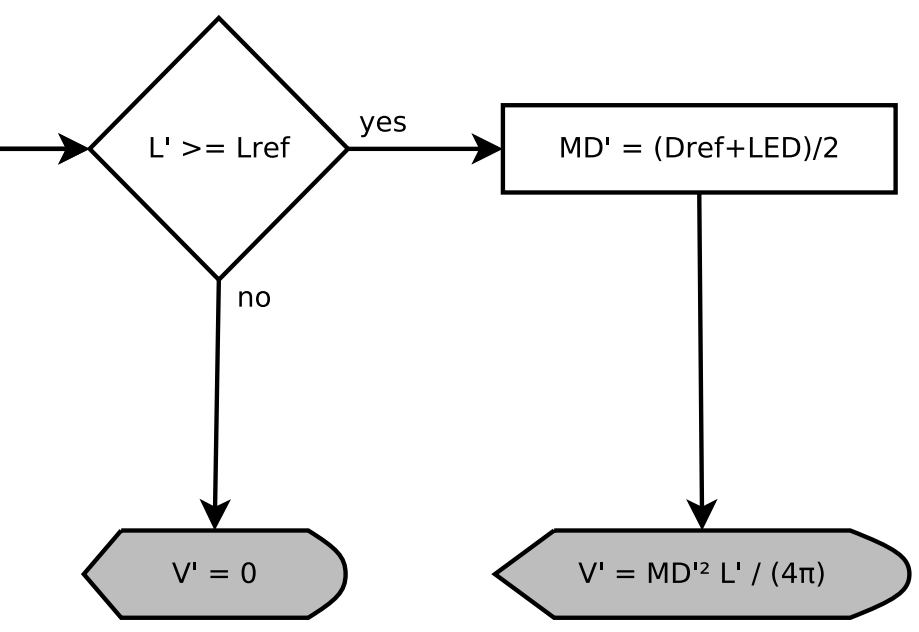

Fig. (4). Bridging function calculation scheme where SED = small-end diameter; $M D=$ mid-diameter, LED = large-end diameter, $\mathrm{L}=$ measured length, $\mathrm{T}=$ tapering rate, Dref $=$ Diameter threshold, Lref $=$ length threshold, $\mathrm{V}^{\prime}=$ transformed CWD volume, $\mathrm{L}^{\prime}=$ transformed CWD length, MD' = transformed CWD MD. 
larger than $6.4 \mathrm{~cm}$. Since the debris length must be known, this procedure could only be used to convert estimates from FAS. It required also an estimate of piece tapering rate in order to estimate small-end diameter (SED) and large-end diameter (LED) which were not measured in the field. For this reason we used stem analyses data that have been used for many years to establish volume functions of commercial tree species in Wallonia [43]. Thanks to this large data set, we simulated debris of stems and branches, and next, we tried to model the tapering rate as a function of debris middiameter, debris length and species. It turned out that no satisfactory model could be found and that using an average tapering rate (of about $1.9 \mathrm{~cm} / \mathrm{m}$ ) can be accurate enough as its impact on total estimated volume is limited.

Secondly, in order to convert volume estimates from LIS, computations are simply executed again including only CWD respecting a new diameter threshold (at the debristransect intersection point).

\subsection{Statistical Analyses}

All the following analyses and simulations were performed with R software [44].

\subsubsection{Sampling Distribution of CWD Volume}

The sampling distribution of CWD volume is far from any classic probability distribution (Fig. 5). In fact, one might name the sampling distribution of CWD volume as a zero-inflated log normal distribution [45]. This specific feature is due to the abundance of null observations. Indeed CWD are most of the time rare and sample units too small. Consequently we computed the proportion of null observations $\left(P_{v_{j}=0}\right)$ to better describe the sampling distribution. Confidence intervals were computed by bootstrapping with 10,000 bootstrap replicates [46].

\subsubsection{Estimate Precision of CWD Volume}

The precision of CWD volume estimates is assessed with the standard error of the mean $\left(\hat{\sigma}_{\bar{v}}\right)$ and the sample variability is expressed with the coefficient of variation ( $C V=\hat{\sigma}_{v} / \bar{v}$ ). The standard error of the mean is computed with the formula adapted to random sampling designs (equation 6).

$\hat{\sigma}_{\bar{v}}=\sqrt{\frac{\sum_{j=1}^{j=n}\left(v_{j}-\bar{v}\right)^{2}}{(n-1) n}}$

It appears logically that smaller sampling units imply greater estimate variability. We therefore drew Bland and Altman's plots [47] to identify possible differences between method estimates as a function of mean CWD volume in two sampling methods.

\subsubsection{Efficiency of Inventory Methods}

The efficiency of an inventory method is usually a formulation combining the precision and the cost. For example, at comparable level of precision, a faster sampling method would be more efficient. We appraised the inventory time trough the number of sampling units and the mean measurement duration in sampling units.

(a)

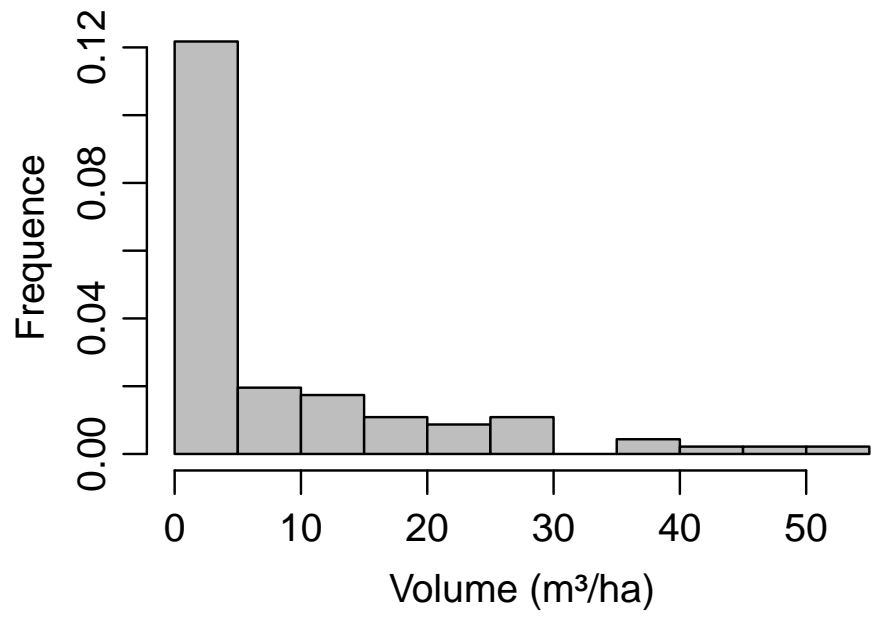

(b)

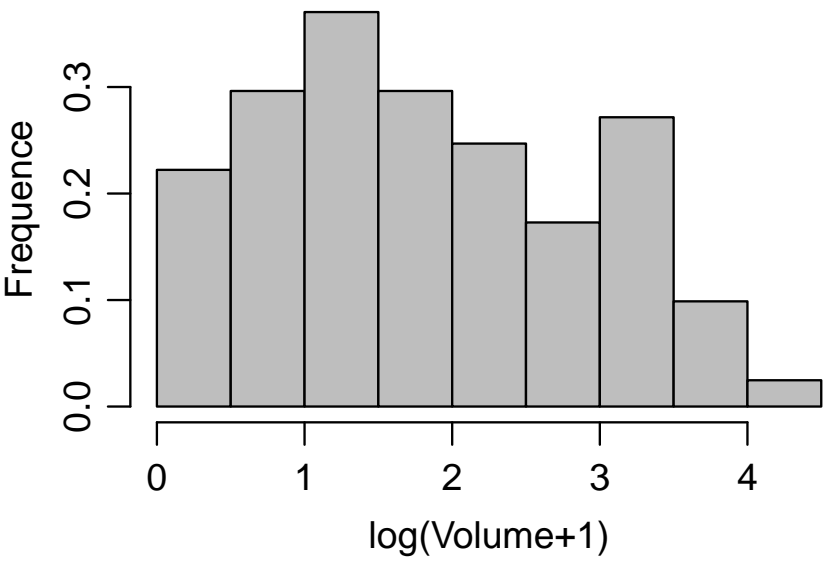

Fig. (5). Sampling distribution of CWD volume (a) and of logarithm of non-null CWD volume (b).

\section{RESULTS}

The CWD volume estimates with respect to the 8 sampling methods are shown in Table 1. The differences between these estimates are noteworthy but not significant.

\subsection{Assessing Precision}

The coefficient of variation, the proportion of null observations and the maximum estimate are the lowest with FAS9, and the highest with LIS18 (Table 1). The precision of FAS9 estimates and LIS36 estimates are very close. In the same way Bland-Altman's plots (Fig. 6) shows that LIS36 and FAS9 seem to provide similar estimates regardless of the mean CWD volume. However estimates from LIS18, or short transect, tends to underestimate CWD volume with respect to FAS9 and LIS36 estimates where CWD amount is low. Conversely LIS18 tends to overestimate deadwood volume when the mean deadwood volume is high. This may result from CWD aggregation within plots and our observation might be simply summarized by: the lower the 
Table 1. Statistics of CWD Volume Per Hectare

\begin{tabular}{|c|c|c|c|c|c|c|c|}
\hline \multirow{2}{*}{ Method } & \multirow{2}{*}{$\boldsymbol{n}$} & $\bar{v}$ & $\hat{\sigma}_{\bar{v}}$ & $\hat{\sigma}_{v}$ & $\boldsymbol{C V}$ & $P_{v_{j}=0}$ & $\mathbf{M a x}$ \\
\cline { 3 - 8 } & & $\left(\mathbf{m}^{\mathbf{3} / \mathbf{h a})}\right.$ & $\left(\mathbf{m}^{\mathbf{3} / \mathbf{h a})}\right.$ & $\left(\mathbf{m}^{\mathbf{3} / \mathbf{h a})}\right.$ & $\boldsymbol{( \% )}$ & $(\boldsymbol{\%})$ & $\left(\mathbf{m}^{\mathbf{3} / \mathbf{h a})}\right.$ \\
\hline \hline LIS18 & 90 & $8.48(5.20-11.78)$ & 1.70 & 16.16 & 190.68 & 56 & 83.51 \\
\hline LIS21 & 90 & $8.17(5.06-11.26)$ & 1.60 & 15.18 & 185.85 & 51 & 91.03 \\
\hline LIS24 & 90 & $7.59(4.76-10.44)$ & 1.46 & 13.84 & 182.20 & 49 & 82.62 \\
\hline LIS27 & 90 & $7.29(4.69-9.88)$ & 1.32 & 12.53 & 171.88 & 44 & 73.44 \\
\hline LIS30 & 90 & $7.23(4.93-9.54)$ & 1.19 & 11.30 & 156.33 & 38 & 66.10 \\
\hline LIS33 & 90 & $7.38(4.94-9.78)$ & 1.22 & 11.61 & 157.19 & 37 & 62.36 \\
\hline LIS36 & 90 & $7.30(5.07-9.52)$ & 1.13 & 10.72 & 146.80 & 32 & 57.16 \\
\hline FAS9 & 90 & $8.37(5.96-10.77)$ & 1.23 & 11.70 & 139.70 & 12 & 54.50 \\
\hline
\end{tabular}

sampling unit size, the greater the variability of CWD volume.

\subsection{Assessing Efficiency}

FAS9 and LIS36 require on average 5.5 minutes and 4 minutes per plot respectively, and this difference is significant (paired t-test: $\mathrm{p}=0.02, \mathrm{n}=51$ ). The efficiency of LIS36 is therefore slightly higher since both methods provide comparable level of precision.

\subsection{Bridging Function}

Fitted curves (Fig. 7) show the relationship between CWD volume and diameter threshold. Both bridging function produces quite similar results even though they were produced with different algorithms and definitions.

\section{DISCUSSION}

Operationally, using transects appears usually easier and faster than using plots. It requires only one measurement: the piece diameter, and secondarily the piece tilt, whereas FAS requires piece length and mid-diameter. Moreover measuring piece length might be difficult as piece's extremities might be buried into the ground, covered up with ground vegetation, and they are partially degraded most of the time. Measuring piece length is highly time-consuming, especially

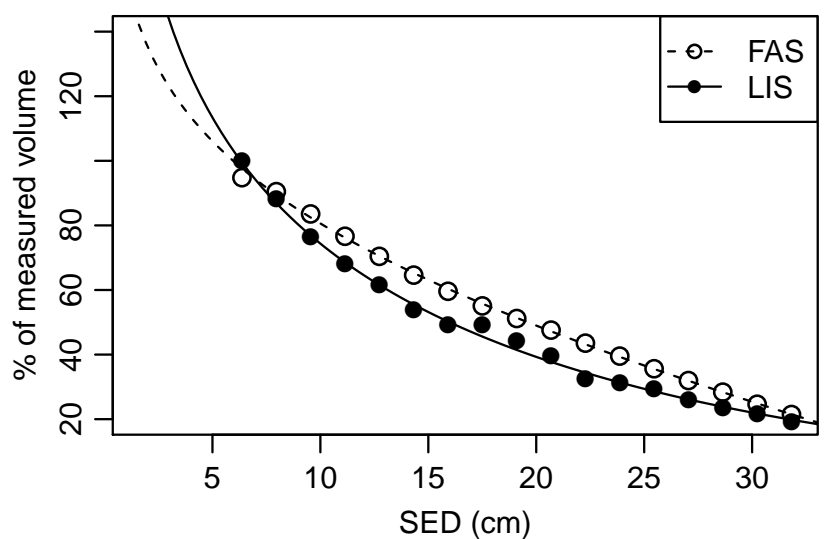

Fig. (7). Bridging function computed to take into account a change in small-end diameter (SED).

if CWD and ground vegetation are abundant within plots. Under such conditions, it would require a large amount of time, while they could measure it more easily with transects. Besides operators measuring CWD in a plot have to remember or mark every measured piece. Measuring CWD along transect is straightforward as debris are measured in a defined order. We must however emphasize that measuring only one diameter per piece with LIS is sufficient for assessing CWD volume, although it results in a loss of information, such as CWD length distribution. In brief, despite some disadvantages, single transect with only one
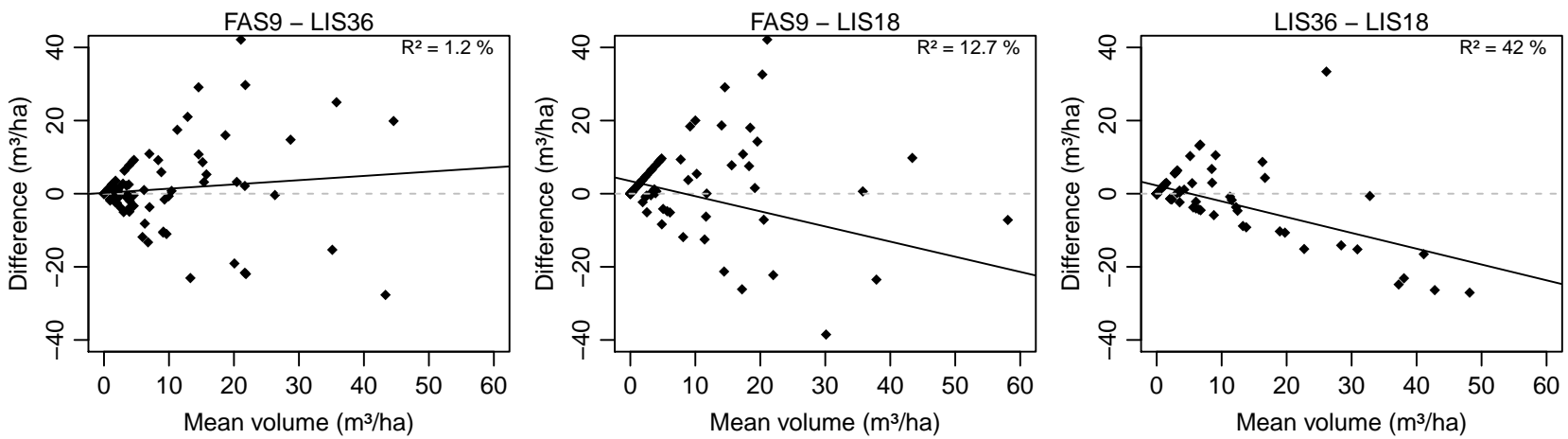

Fig. (6). Bland and Altman's plots to compare differences between inventory methods. The smaller the sampling unit, the greater the variability of CWD volume estimates. 
measure of girth per debris might appear more suitable than FAS to assess CWD volume especially in forests with abundant deadwood and/or a high cover of ground vegetation.

The precision of estimates remains rather weak regardless of the method used $\left(15 \%<\hat{\sigma}_{\bar{v}} / \bar{v}<20 \%\right)$. Mainly the sampling size should have been greater to obtain a better precision. Among them, FAS with plots of 9-m radius provide the most precise estimates. However the precision of 36-m transects is not significantly lower. Using 36-m transects might be slightly more efficient than using plots of $9-\mathrm{m}$ radius because they generate a gain of 1.5 minutes. However, this gain of time is negligible for the RFIW crew. Indeed, in multi-resource inventories, deadwood is only one of the numerous variables assessed. For example one field crew of the RFIW stays on average about one hour per plot.

Our findings depend however on the thresholds used ( $\mathrm{SED}>6.4 \mathrm{~cm}$ and $\mathrm{L}>1 \mathrm{~m}$ ) and on the abundance, the heterogeneity, and the patchiness of CWD. For example, Parminter et al. [48], who compared samplings of logs, recommends a sampling effort of $4.5 \mathrm{~m}$ of transect per hectare. Woldendorp et al. [29] formulate that the more seldom CWD are, or the more heterogeneous their spatial distribution is, the bigger the sampling units should be. Moreover McKenzie et al. [26] report that $625-\mathrm{m}^{2}$ plots should be used if they include less than 10 debris, otherwise 20-m transects should be preferred. In brief, all confirm that the higher the density of CWD, the smaller the sampling units could be. When CWD are abundant within sampling units, LIS appears often more efficient that FAS. Besides, increasing threshold decreases CWD density and the number of tallied debris, which might penalize LIS. Under the conditions of the Walloon forest, where CWD volume is weak (less than $5 \mathrm{~m}^{3} /$ ha, and about $8 \mathrm{~m}^{3} /$ ha in this study), LIS did not appear a real advantageous solution, as it did in other the studies $[13,33]$.

Alternatively we might expect very different conclusions with local CWD inventories (e.g. an inventory carry out at the scale of a forest property). We focused on multi-resource inventory for which a good sampling method must fit the global inventory design and thus the number of sampling units and their sizes are restricted. On the other hand local scale inventories have usually less constraints and, therefore, other sampling units, like longer transects, could be utilized more efficiently than plots of 9 m radius.

In addition harmonizing CWD estimates appeared to be crucial. CWD definition is amazingly complicated but a change in this definition might have a strong impact on CWD volume estimates. We estimated that a coefficient of about 0.8 is required to harmonize RFIW estimates in order to meet the international reference. Also the extrapolation of the bridging function indicates that small debris might have a significant impact on total volume estimates. This illustrates well the importance of inventory definitions and thresholds and it should encourage inventory manager to build bridging functions.

Bridging function was successfully developed in order to convert estimates from FAS. On the other hand, the bridge for LIS estimates does not really seem advisable. Indeed, CWD length was not measured along transects, although it remains an important variable for the harmonizing procedure. An increase in the SED threshold implies that the measured sections of CWD are shorter and sometimes even shorter than the length threshold. Consequently, comparisons of CWD volume between LIS and FAS might remain deficient.

Besides we restricted our study to a very limited number of sampling techniques and protocols. Y-shaped transects, like those used by the Swiss and American inventories, would have increase the sampling effort and hence the precision and the measurement duration. Similarly debris length and mid-diameter can be measured along transects. This way, bridging function can be more easily adapted to LIS estimates but this is offset by the measurement duration. Relascopic sampling methods are also other sampling methods to consider. Those methods are mainly efficient because field measurements are reduced. But, once again, it might induce a loss of information that could impede the development of bridging functions.

Finally we hold interest only in total volume estimates. Nonetheless CWD is often classified in different decay classes and next the CWD biomass or carbon contents can be computed. Measuring the decay of debris would certainly increase the measurement duration and FAS would probably be more affected since the number of tallied debris in plots is higher than in transects.

\section{CONCLUSIONS}

According to our results concerning time requirement and precision, LIS appears slightly more efficient. Nevertheless, FAS remains more appropriate to the needs of the regional forest inventory of Wallonia. The use of transects did not clearly improve precision, and rather leads to a loss of information, while impeding the development of bridging functions. Bridging functions can, however, be easily and accurately developed from FAS estimates. They are next used to harmonize CWD volume estimates which we highly recommend given that a small change in the thresholds of debris dimensions can induce a significant effect in total CWD volume estimate. Nevertheless the best sampling method depends largely on local conditions (CWD size, abundance and spatial distribution), applied thresholds, general inventory design, and inventory objectives. Mainly we believe our findings to be limited to forests with low abundance of CWD which often occurs in managed forests.

\section{ACKNOWLEDGEMENTS}

Declared none.

\section{CONFLICT OF INTEREST}

\author{
Declared none.
}

\section{REFERENCES}

[1] Samuelsson J, Gustafsson L, Ingelog T. Dying and dead trees. A review of their importance for biodiversity. Uppsala : Swedish Threatened Species Unit 1994. 
[2] Schuck A, Meyer P, Menke N, Lier M, Lindner M. Forest biodiversity indicator: dead wood-a proposed approach towards operationalising the MCPFE indicator. In: Marchetti M, Ed. Monitoring and Indicators of Forest Biodiversity in Europe - From Ideas to Operationality. Joensuu, EFI Proceedings 51. 2004; pp. 49-77.

[3] Ruiz-Peinado R, del Rio M, Montero G. New models for estimating the carbon sink capacity of Spanish softwood species. For Syst 2011; 20: 176-88.

[4] Radu S. The ecological role of deadwood in natural forests. Nat Conserv 2006; 3: 137-41.

[5] Bernier N. In: Daniel V, Jean A, Benoît D, Richard EM et Dominique R, Eds Bois mort et cavité: une clef pour des forêts vivantes. Paris: Lavoisier 2005; pp. 99-104.

[6] Lausch A, Fahse L, Heurich M. Factors affecting the spatio-temporal dispersionof Ips typographus (L.) in Bavarian Forest National Park: A longtermquantitative landscape-level analysis. For Ecol Manage 2011; 261: 233-45.

[7] Fuhrman NE. An analysis of the ecology and public perception of coarsewoody debris in Virgina. MS Thesis. Virginia: Faculty of the Virginia Polytechnic Institute and State University 2004.

[8] Cocher G. In : Daniel V, Jean A, Benoît D, Richard EM et Dominique R, Eds Bois mort etcavité: une clef pour des forêts vivantes. Paris : Lavoisier 2005; pp. 119-24.

[9] Van Wagner CE. The line intersect method in forest fuel sampling. For Sci 1968; 14: 20-6.

[10] De Vries PG. Sampling theory for forest inventory: a teach-yourself course. New York:Springer-Verlag 1986.

[11] Marshall PL, Davis G, Taylor SW. Using Line Intersect Sampling for CoarseWoody Debris: practitioner's questions addressed.Vancouvert: Forest Research Extension Note 2003.

[12] Kangas A. In: Kangas A, Maltamo M, Eds. Forest Inventory Methodology and Application. The Netherlands: Springer 2006; pp. 119-37.

[13] Böhl J, Brändli UB. Deadwood volume assessment in the third Swiss National Forest Inventory: methods and first results. Eur J For Res 2007; 126: 449-57.

[14] Williams MS, Gove JH. Perpendicular distance sampling: an alternative method for sampling downed coarse woody debris. Can J For Res 2003; 33: 1564-79.

[15] Williams MS, Valentine HT, Gove JH, Ducey MJ. Additional results forperpendicular distance sampling. Can J For Res 2005; 35: 961-6.

[16] Gove JH, Ringvall A, Ståhl G, Ducey MJ. Point relascope sampling ofdowned coarse woody debris. Can J For Res 1999; 29:1718-26.

[17] Gove JH, Ducey MJ, Ståhl G, Ringvall A. Point relascope sampling: A new way to assess downed coarse woody debris. J For 2001; 99: 4-13.

[18] Ståhl G, Ringvall A, Gove JH, Ducey MJ. Correction for slope in point and transect relascope sampling of downed coarse woody debris. For Sci 2002; 48: 85-92.

[19] Ståhl G. Transect relascope sampling -a method for the quantification of coarse woody debris. For Sci 1998; 44: 58-63.

[20] Ringvall A, Ståhl G. Field aspects of line intersect sampling for assessing coarse woody debris. For Ecol Manage 1999; 119: 163-70.

[21] Bebber DP, Thomas SC. Prism sweeps for coarse woody debris. Can J For Res 2003; 33: 1737-43.

[22] Thompson SK. Adaptive cluster sampling. J Am Stat Assoc 1990; 85: 1050-9.

[23] Turk P, Borkowski JJ. A review of adaptive cluster sampling: 19902003.Environ Ecol Stat 2005; 12: 55-94.

[24] Talvitie M, Leino O, Holopainen M. Inventory of sparse forest populations using adaptive cluster sampling. Silva Fennica 2006; 40:101-8.

[25] Bell G, Kerr A, McNickle D, Woollons R. Accuracy of the line intersectmethod of post-logging sampling under orientation bias. For Ecol Manage 1996; 84: 23-8.

[26] McKenzie N, Ryan P, Fogarty P, Wood J. Sampling, measurement and analytical protocols for carbon estimation in soil, litter and coarse woody debris. National Carbon Accounting System Technical Report No. 14. Canberra: Australian Greenhouse Office 2000.

[27] Lutes DC. Assessment of the Line Transect Method: An Examination of the Spatial Patterns of Down and Standing Dead Wood. In:
Laudenslayer JWF, Shea PJ, Valentine BE, Weatherspoon CP, Lisle TE, Eds. Proceedings ofthe Symposium on The Ecology and Management of Dead Wood in Western Forests. Albany, USDA Forest Service 2002; pp. 665-75.

[28] Nemec AFL, Davis G, Section R, Region VF. Efficiency of six line intersect sampling designs for estimating volume and density of coarse woody debris. Technical Report. TR-021 Vancouvert: Forest Research Technical Report 2002.

[29] Woldendorp G, Keenan R, Barry S, Spencer R. Analysis of sampling methods for coarse woody debris. For Ecol Manage 2004; 198: 133-48.

[30] Bate LJ, Torgersen TR, Wisdom MJ, Garton EO. Performance of sampling methods to estimate log characteristics for wildlife. For Ecol Manage 2004; 199: 83-102.

[31] Jordan GJ, Ducey MJ, Gove JH. Comparing line-intersect, fixed-area, and point relascope sampling for dead and downed coarse woody material in a managed northern hardwood forest. Can J For Res 2004; 34:1766-75.

[32] Pesonen A, Leino O, Maltamo M, Kangas A. Comparison of field sampling methods for assessing coarse woody debris and use of airborne laser scanningas auxiliary information. For Ecol Manage 2009; 257: $1532-41$.

[33] Teissier du Cros R, Lopez S. Preliminary study on the assessment of deadwood volume by the French national forest inventory. Ann For Sci 2009; 66: 302.

[34] Köhl M, Traub B, Päivinen R. Harmonisation and standardisation in multinationalenvironmental statistics-mission impossible? Environ Monit Assess 2000; 63: 361-80.

[35] Vidal C, Lanz A, Tomppo E, et al. Establishing forest inventory reference definitions for forest and growingstock: a study towards common reporting. Silva Fennica 2008; 42: 247-66.

[36] Erkki T, Thomas G, Mark M, Ronald EM, Lawrence M, Eds. National forest inventories: pathways for common reporting. The Netherlands: Springer 2010.

[37] McRoberts RE, Tomppo E, Schadauer K, et al. Harmonizing national forest inventories. J For 2009;107: 179-87.

[38] McRoberts RE, Ståhl G, Vidal C, Lawrence M, Tomppo E, Schadauer K. National forest inventories: prospects for harmonised international reporting. In: Erkki T, Thomas G, Mark M, Ronald EM, Lawrence M, Eds. National forest inventories: pathways for common reporting. The Netherlands: Springer 2010; pp. 33-44.

[39] Rondeux J, Sanchez C, Latte N. Development of the regional forest inventory (RFI) in Wallonia. In: Erkki T, Thomas G, Mark M, Ronald EM, Lawrence M, Eds. National forest inventories: pathways for common reporting. The Netherlands: Springer 2010; pp. 73-88.

[40] Affleck DLR, Gregoire TG, Valentine HT. Design unbiased estimation in lineintersect sampling using segmented transects. Environ Ecol Stat 2005; 12: 139-54.

[41] Green P, Peterken GF. Variation in the amount of dead wood in the woodlands of the Lower Wye Valley, UK in relation to the intensity of management. For Ecol Manage 1997; 98: 229-38.

[42] Kangas A, Maltamo M, Eds. Forest inventory - methodology and application. The Netherlands: Springer 2006; pp .13-38.

[43] Dagnelie P, Palm R, Rondeux J, Thill A. Tables de cubage des arbres et des peuplements forestiers. Belgium: Les presses agronomiques de Gembloux 1999.

[44] R Development Core Team. R: A Language and Environment for Statistical Computing. Vienna, Austria 2009. Available form: http:// www.R-project.org [Accessed: 25 May 2012].

[45] Tian L. Inferences on the mean of zero-inated lognormal data: the generalized variable approach. Stat Med 2005; 24: 3223-32.

[46] Adèr HJ, Mellenbergh GJ, Hand D. Advising on research methods: A consultant's companion. Huizen, The Netherlands: Johannes van Kessel 2008.

[47] Bland JM, Altman DG. Statistical methods for assessing agreement betweentwo methods of clinical measurement. Lancet 1986; 1: 307-10.

[48] Parminter J. Coarse woody debris sampling intensity considerations. Victoria: Ministry of Forests 1998. Available form: http://www.for. gov.bc.ca/hre/deadwood/DTmes5.htm [Accessed: 25 May 2012]. 